\title{
Current Trends in ELT Educational Communication during Crises: An Overview to the Special JLE Issue
}

\author{
Salvador Montaner-Villalba ${ }^{1}$, Jesús García-Laborda ${ }^{2}$ \\ ${ }^{1}$ Universitat Politècnica de València \\ ${ }^{2}$ University of Alcalá \\ Correspondence concerning this article should be addressed to Salvador Montaner-Villalba, Universitat \\ Politècnica de València, Camí de Vera, s/n 46022 València, Spain. E-mail: smonvil@idm.upv.es
}

\begin{abstract}
The sudden emergence of Covid-19 which began in March 2020 up to these days in December 2021 has brought to us, overall, new habits of living and, more specifically, educators as well as language instructors from all over the world have had the urgent need to rapidly change teaching habits so as to adapt to an online teaching due to this pandemic. This special issue offers the readers new approaches and trends on the teaching and learning process of English as a foreign language through various indeed interesting experiments which have taken place at different educational setting during the forced lockdown caused by the pandemic crisis of the Covid -19 .
\end{abstract}

The issue begins with the editorial article headlined Covid-19: an impromptu or trend-setting factor in research on language and education? (by L. Raitskaya and E. Tikhonova).

We will try to summarize the different papers from this issue on ELT during the Covid-19 pandemic. Firstly, we start with an overview of the eleven research scientific papers. The first paper headlined Dealing with Emergency Remote Teaching: The Case of Pre-Service English Language Teachers in Turkey by R. Ağçam, Y.E. Akbana, and S. Rathert, offers a qualitative study in which the perceptions of a group of 67 pre-service English language teachers on Emergency Remote Teaching (ERT) practices were explored. An interview form and a focus group interview were chosen to obtain findings. The obtained data in this research proved that the majority of the participating student preferred face-to-face lessons than ERT emerged due to the pandemic. The authors of this study focus on the need to help both students and instructors by offering strategies and instructions on how to organise learning and teaching. Ağçam, Akbana, and Rathert conclude by advising the different ELT stakeholders to take advantage of ERT's opportunities.

Secondly, the article Online Learning During the Covid-19 Pandemic: How Has this new Situation Affected Students' Oral Communication Skills? by E. Alcalde-Peñalver and J. García-Laborda investigated the difficulties faced by students learning English within the online learning context, paying special attention to oral communication skills. For this purpose, the authors utilized an exploratory survey research design with the aid of a questionnaire. The findings of this research proved that learners highlighted technical problems as some of the main challenges, and they did not feel completely comfortable in the online learning environment because oral communication was completely absent. The participating students also found group video or audio calls to be the most useful tool for enhancing oral communication in English.

Thirdly, the next research headlined Account of a Foretold Death: Analysing the Response to the Pandemic in Spanish Schools by A. Chabert concentrated on the relevance of technology accessibility as well as digital competence within the language learning process during Covid-19. The author of this qualitative research analysed and contrasted with the aid of questionnaires on the manner schools and educators in the Valencian region (Spain) helped learners during the confinement in primary education. Through different interviews to teachers from four schools in the province of Castellon, Chabert examined and compared between the nowadays reality of the use of technology in primary school and the national guidelines as well as frameworks offered for teachers.

The fourth article Who Wants to Learn English Online for free? authored by R. Chacón-Beltrán and R. Echitchi is aimed through their demographics research at assisting LMOOC developers and, more specifically EFL MOOCs 
in Spanish-speaking settings, improving more appealing courses for future learners, taking also into consideration that alternative learning approaches, such as the MOOC, are necessary due to the Covid-19 pandemic. With the aid of a questionnaire, the findings of this qualitative research showed that most learners were middle-aged adults who had completed a university degree. Moreover, results of this research apparently indicate that female learners are more likely to take the courses than their male counterparts. Overall, these findings represent a good starting point for further research with the main purpose of helping educational authorities know how positive LMOOCS could be to reach a wider audience.

The next article $A$ Telecollaboration Project on Giving Online Peer Feedback: Implementing a Multilateral Virtual Exchange During a Pandemic by M. J. Ennis, M. Verzella, S. Montanari, A. M. Sendur, M. S. Pissarro, S. Kaiser, and A. Wimhurst dwelled upon telecollaboration as a tool to enhance language skills acquisition, intercultural competence, and digital literacies. These authors described a case of a multilateral telecollaboration project designed to train students on developing collaborative writing tasks. This experiment took place during the Covid-19 pandemic since there was a sudden switch to remote teaching and learning. With the aid of various data sources, such as correspondence, observations, class discussions, surveys, reflective writing, etc, the findings of this research demonstrated that even during a global pandemic, both students and teachers face similar logistical challenges. Yet, this research reveals the resiliency of telecollaboration in the face of extreme disruption and its didactic possibilities to exploit virtual exchange so as to develop learning strategies (such as methods for giving and receiving peer feedback) and meta-awareness of how language is utilized in the realworld (such as the implications of English as a lingua franca).

The sixth paper headlined The Language of Russian Fake Stories: A Corpus-Based Study of the Topical Change in the Viral Disinformation Spread During the First Year of the Covid-19 Pandemic authored by A. Monogarova, T. Shiryaeva, and N. Arupova, considered the outcomes of a corpus-based study of Russian viral fake stories which circulated during the year of 2020, the first year of the Covid-19 pandemic. The authors proposed a specific method to analyse the both the main themes as well as the dynamics of topical change within the context of the Russian Covid-19 fake story. To this end, a set of tools for extract keywords and their frequencies counts were utilized. The authors evaluated the obtained findings to determine the dynamics of thematic shifts by tracking the changes in keyword frequencies as well as the use of other high-frequency corpus words.

In the seventh article headlined Students' Perceptions of ESP Academic Writing Skills through Flipped Learning during Covid-19 written by S. Montaner-Villalba, the author focused on analysing university students' perception of ESP academic writing skill and, more specifically, Business English written competence in the Valencian Polytechnic University within the context of the online learning during the pandemic Covid-19 utilizing the Flipped Learning approach. The findings obtained in this research proved that the outcomes were positive since most of them showed students' awareness of their needs and ESP written requirements.

A. Otto and B. López Medina, in their article Promoting Metacognitive and Linguistic Skills: Digital Learning Logs in Pre-Service Teacher Training, report on the implementation of digital learning logs within an online education university in Madrid (Spain) in the context of pre-service teacher training. This paper is aimed, firstly, at analysing whether the learning logs assisted to enhance learners' autonomy as well as self-reflection and, secondly, to observe whether these learning logs contribute to the improvement of students' linguistic competence using the English language. Participants of this research $(n=47)$, from the Primary and Infant Education degrees, specializing in Didactics of the English language, were required to complete a digital questionnaire on their own experience utilizing the logs, answering questions as for the suitability of logs so as to promote students' language skills and enhance effective strategies to gain autonomy as learners. Additionally, individual semi-structured interviews were carried out to gather information on those students who had not completed the learning $\log (\mathrm{n}=11)$. The outcomes of this research proved that a huge number of participants agree on the didactic possibilities of learning logs not only as a useful tool to keep track of their learning process but also to improve linguistic skills and metacognitive awareness.

The next article headlined Pandemic Language Teaching: Insights from Brazilian and International Teachers on the Pivot to Emergency Remote Instruction authored by A. Sevilla-Pavón and K. R. Finardi reflected on language teachers' experiences from Brazil, Spain, France, Cyprus, Costa Rica, and Taiwan during the pivot to emergency remote teaching during the 2020 pandemic. In particular, the authors were aimed at describing these teachers' perceptions regarding online teaching during Covid-19. Mixed method, consisting of an online questionnaire 
as well as focus group interviews, were utilized so as to analyse the data of this research. Whereas, on the one hand, the findings of the questionnaire showed negative aspects, such as that a huge number of participating students did not feel prepared enough due to lack of institutional support and training, the results of the focus group interviews indicated that a vast number of educators showed concerns regarding the limitations of virtual teaching for both examination and interacting, on the other hand, some positive aspects included a chance to develop moreself-directed and autonomous learning. This research overall suggests that, after the pandemic and with due training, some of the online technologies and approaches experimented with will be included into pedagogical practices in hybrid learning, representing a real trend and possibility for language teaching in the post-pandemic context.

The tenth paper Assessment under Covid-19: Exploring Undergraduate Students' Attitudes towards their Online Thesis Proposal Presentations vs. Face-to-face Presentations by O. Stognieva and V. Popov is based on the study conducted in the EFL classroom during the fourth year of a Business Informatics degree. It investigated students' perceptions of the thesis proposal presentation involving a Skype online presentation and students' end-of-course assessment experience in the context of online learning during the Covid-19 pandemic at HSE University in Moscow. To analyse the data obtained in this study, a mixed-method approach utilizing both quantitative and qualitative data was applied. The findings of this mixed-method research indicated that emergency transition to the online teaching did not affect students' satisfaction or the outcomes of the oral presentation. The authors of this paper conclude giving recommendations for language instructors and students.

The last research paper of this special issue is headlined An Appraisal Look into Shielded Online Education in Covid Era: Resilience Revisited and authored by M. Teimortash and M. Teimortash. The article aimed to depict the adversities exerted when online education was required to be implemented due to the Covid-19 spread in Islamic Azad University Tehran. Since the notion of resilience could be introduced in the context of online education, a resilience questionnaire was conducted before and after an online course in the second semester of the year 2020-2021 with undergraduate EFL students specialising at Translation Studies. This Resilience Questionnaire was collected from both the treatment group as well as the control group. The findings obtained through quantitative method showed that shielded distance courses outperformed significantly in promoting students' resiliency during the pandemic era.

In addition to research articles, the special JLE issue brings out several reviews and studies. Thus, the publication headlined From On-site to online class: The Role of Mediation in Online Teaching Simulation by O. Polyakova and B. Pastor-García presented the outcomes of a pilot study at the Catholic University of Valencia exploring the relationship between mediation and teaching simulation tasks during a postgraduate course for CLIL (Content and Language Integrated Learning) during the lockdown occurred in Spain due to the pandemic crisis and, thus, held online. The findings of this research were the display of feasibility of the curricular adaptation by offering (1) CLIL teaching simulation planning, (2) teaching simulation assessment sheet and (3) questionnaire responses. These three considerations were closely related to both mediation as well as online education. The authors proved that this research yielded positive effects of the CLIL approach. For this reason, the authors of this paper recommend developing the connection between mediation, online instruction and CLIL teacher training opportunities implementing the lessons learned in an authentic school context.

The systematic review headlined Language Education in Emergencies: A Systematic Review of Empirical Research is authored by A. Thumvichit, S. Varaporn, and V. Tuvachit. These researchers bring together the available research within the field of language learning and teaching in the current emergency context so as to analyze the state of affairs, and the situation's inherent challenges and opportunities for both language instructors and learners. The authors of this systematic review article included a total of 38 studies in order to reflect the current trend, with 16 of these in-depth reviewed. A vast number of publications were carried out in the context of University education. Thumvichit, Varaporn and Tuvachit conclude their work, highlighting that teachers do their best to retain their teaching principles and implement them regardless of the abrupt transition.

This special issue on Current trends in ELT during the Covid-19 ends with a review of the book entitled University and School Collaborations during a Pandemic. Sustaining Educational Opportunity and Reinventing Education (2022) edited by Fernando M. Reimers and Francisco J. Marmolejo. The book review is authored by Anastasia V. Lazareva. 
As seen from this brief introduction, the special issue addresses a wide range of interesting topics relevant not only to the current world crisis but to other complicated situations in language learning and teaching. It is selfevident that technology and active participation of different educational stakeholders play a significant rule in overcoming the constraints that teaching during crises bring about. In this sense, this special issue is a good collection of experiences that can provide ideas to both researchers and practitioner teachers. It is the editors' hope that the potential readers will enjoy this special issue as much as we did when preparing it. We want to extend our gratitude to the authors who wrote, revised and worked thoroughly on their papers, to all the reviewers who gave suggestions on improving the original submissions, and also to the JLE editors who gave us the possibility to provide the international readership with life experiences that have changed the way we currently understand Language \& Education. 